\title{
Oregano Leaf Oil
}

National Cancer Institute

\section{Source}

National Cancer Institute. Oregano Leaf Oil. NCI Thesaurus. Code C107338.

The essential oil of Orig anum vulgare. Oregano oil has antibacterial and antifungal properties. 